\title{
Design of High Temperature Thermal Energy Storage for High Power Levels
}

\author{
Maike Johnson $^{1}$, Julian Vogel $^{1}$, Matthias Hempel ${ }^{1}$, Bernd Hachmann ${ }^{2}$, Andreas Dengel ${ }^{3}$ \\ ${ }^{1}$ German Aerospace Center (DLR), Pfaffenwaldring 38-40, 70569 Stuttgart, Germany \\ ${ }^{2}$ F.W. Brökelmann GmbH \& Co. KG, Oesterweg 14, 59469 Ense-Höingen, Germany \\ ${ }^{3}$ Steag New Energies, St. Johannerstraße 101-105, 66115 Saarbrücken, Germany
}

*Corresponding email: maike.johnson@dlr.de

Keywords: Latent heat; thermal energy storage; PCM; extended fin; integration; cogeneration

\begin{abstract}
A latent heat thermal energy storage unit has been modeled, simulated and designed for integration into a cogeneration plant that supplies steam to industrial customers in Saarland, Germany. The design consists of a vertical bundle of extended finned tubes surrounded by phase change material in the shell. The heat transfer fluid water/steam flows through the tubes between the upper and lower headers. A new fin design was developed to achieve the required high power levels.

The storage system was designed and analyzed with the development of an iterative multi-step method. The method spans from the design of the fin, based on both empirical and geometrical information, to the heat transfer analysis of a storage system. The analysis is comprised of several steps: a heat transfer analysis of the cross-section of one tube without modeling the heat transfer fluid, a transfer from the cross-section to a simplified onedimensional radial model and a two-dimensional axial and radial analysis coupling the axial flow of the heat transfer fluid and the radial heat transfer into the storage. The developed analysis method and the resulting storage system are presented and the comparison of different fin designs shows the suitability of each fin for different applications.
\end{abstract}




\section{INTRODUCTION}

A thermal energy storage unit is to be integrated into a cogeneration plant. This storage will act as an intermediate back-up to a gas turbine coupled with a heat recovery steam generator (HRSG), so it is situated in parallel to the HRSG, between the feedwater pump and the steam main. This layout is shown in Figure 1. This plant produces steam for several customers, including one with very specific and constant steam quality requirements.

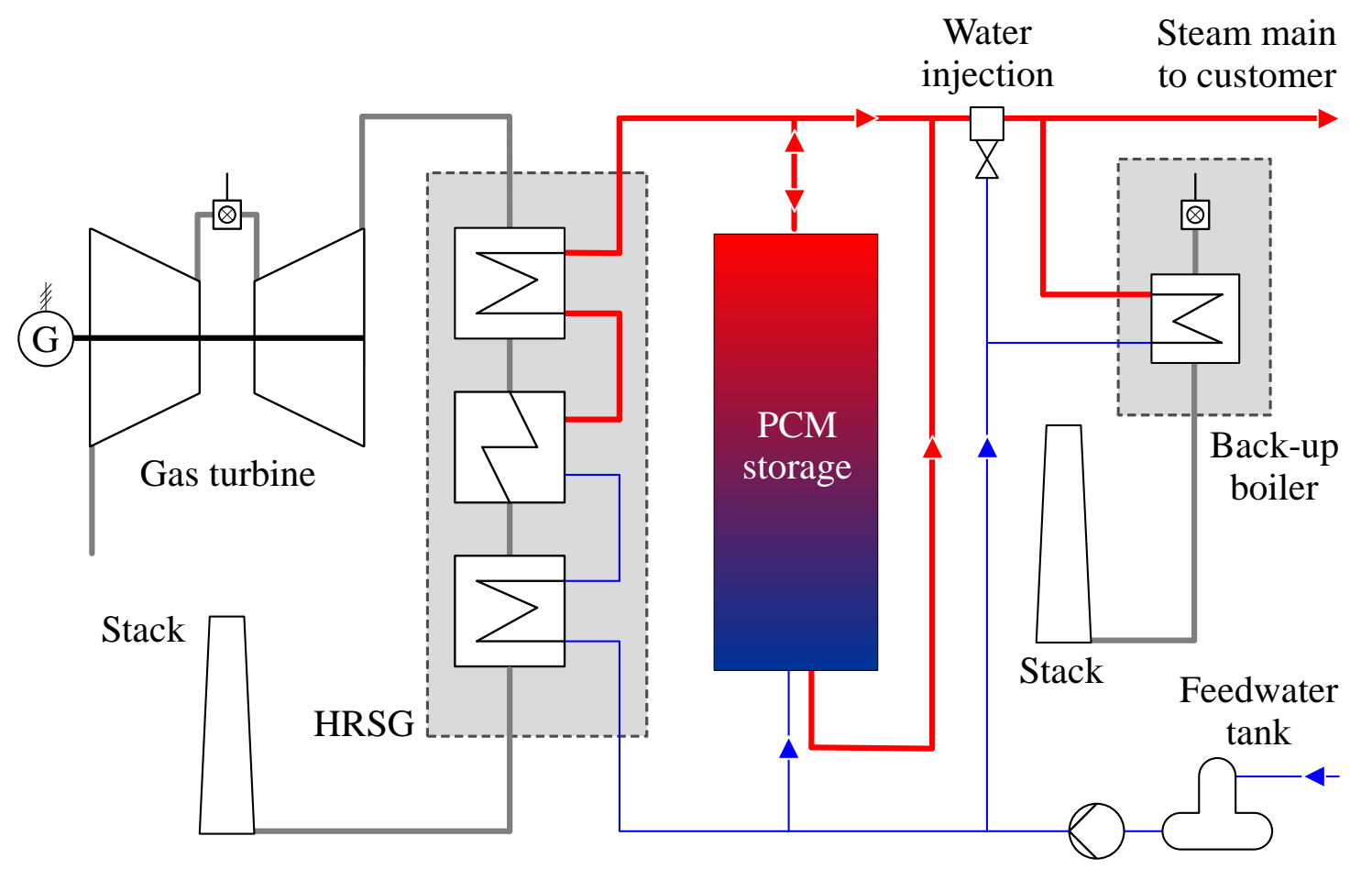

Figure 1: Layout of the cogeneration plant showing the latent heat thermal energy storage integrated in parallel to the HRSG and the back-up boiler.

Currently, a fossil-fuel fired standby boiler is maintained at warm load and in the case of a turbine trip, is heated from warm to full load in two minutes. The storage unit will be integrated so that it is kept on standby and the backup boiler will be reduced to cold load, which requires significantly less fossil fuel. From cold load, the backup boiler needs 15 minutes to reach full load. During this time, the storage unit will produce the required $6 \mathrm{MW}$ of superheated steam at 26 bar and a minimum of $300{ }^{\circ} \mathrm{C}$ for the industrial customer. This combination of parameters leads to a minimum required capacity of $1.5 \mathrm{MWh}$. The standby storage unit is being developed as a latent heat energy storage unit. Using the latent heat of 
fusion of the storage material side with a solidification temperature near the required steam temperature, the volume of the entire storage unit is reduced in comparison to a sensible heat storage unit. Latent heat energy storage allows for a leveling of the discharge temperature due to isothermal phase change. The planned integration is discussed in more detail by Johnson et al. [1].

\section{METHODOLOGY}

Preliminary design considerations and a combination of heat transfer simulation methods are used for the development of a latent heat thermal energy storage unit for a specific application, and moreover one that produces superheated steam,.

\subsection{PRELIMINARY DESIGN}

The system into which the storage unit is to be integrated determines the required parameters: charging and discharging temperature, pressure and heat transfer fluid (HTF), discharging power and capacity. As the HTF in this system is water/steam, a latent heat thermal energy storage using the heat of fusion for heat storage was developed. Both the HTF and the phase change material (PCM) maintain a constant temperature during phase change, which allows for small temperature differences between the two media during both charging and discharging [2]. The inherent properties of the storage material determine the phase change temperature and heat of fusion, so that a storage material must be selected that is appropriate for the system requirements, specifically for the pressure and temperature of the HTF. Based on the system parameters for charging and discharging the storage unit, sodium nitrate $\left(\mathrm{NaNO}_{3}\right)$ with a melting temperature of $306{ }^{\circ} \mathrm{C}$ and a latent heat of $178 \mathrm{~J} / \mathrm{g}$ was chosen as the storage material.

Ideally, the storage material has a high thermal conductivity in order to charge and discharge quickly. However, most applicable materials have low thermal conductivities [3]. 
To overcome low thermal conductivity, various designs and storage concepts have been researched and tested [4]. In this case, a vertically finned tube concept using extruded aluminum fins clipped onto steel tubes was chosen. The developed storage system design is an adaptation of a shell and tube heat exchanger, with extended finned tubes mounted between two headers and the PCM storage medium on the shell side of the tube bundle. The HTF evaporates in the tube bundle. Various storage units at DLR have been tested with extended fins [5], including an evaporator/condenser storage [6].

As the storage unit required by the system in this project requires only 15 minutes of discharge time, the ratio of power level to capacity is very high. In the latent heat TES unit built and tested within the ITES project in Carboneras, Spain, a capacity of ca. $700 \mathrm{kWh}$, a peak power level of ca. $700 \mathrm{~kW}$ [6] and steady-state of $200 \mathrm{~kW}$ were measured [7]. Due to the higher ratio of power to capacity required in this application, both a smaller tube spacing and a denser fin structure are required. The tube spacing has been set at a triangular formation to optimize the space between tubes, which results in a regular hexagonal spacing of the tubes.

With this spacing, an empirically designed axial fin is drafted. Due to the method of aluminum extrusion, the initial design combines manufacturing feasibility, assembly techniques and heat transfer requirements. The extrusion feasibility must be considered: the ratio of length-to-width of the areas between the branches of aluminum has to be small in order to avoid a failure in the tooling for the extrusion. A fixation nub for the clips and room for assembly of the clips over the two fin halves have to be incorporated as well.

The heat transfer aspects of the design allow for heat to be transferred between the HTF and the PCM. For high power levels, the distance or resistance from the storage material to the HTF needs to be minimized, as researched by Sciacovelli \& Verda [8], Hübner et al. [9], and Ziaei et al. [10]. Research from Sciacovelli \& Verda approached the problem with CFD calculations including calculations of entropy generation in an iterative design process. 
Hübner et al. also used an iterative design approach with two-dimensional calculations, analyzing the designs for discharging parameter comparisons and including economic considerations in the comparisons. Ziaei et al. uses a constructal analytical approach for the calculations of the charging characteristics, analyzing the effects of branching on the melting characteristics. Reduction of this resistance can be achieved with evenly distributed highly conductive aluminum introduced into the storage material. The simplest such design is a star form, with 'rays' going out from a central tube. This results in a large proportion of the aluminum near the central tube, with much less material further from the tube. To have a better heat transfer between the outer areas of storage material and the central tube, a branched design was developed, so that in the outer areas of the fin the surface area is further increased by branches in the fin.

\subsection{NUMERICAL HEAT TRANSFER MODEL}

For the numerical simulation of the heat transfer, a subsystem of the tube register, consisting of a single tube with mounted fins and surrounding PCM, is simulated; see Figure 2 (a). The HTF flows through the tube and evaporates or condenses while transferring heat to or from the PCM. Because of the complex geometry with different fluid and solid zones as well as a long tube length, the system is simplified to reduce the simulation effort. Three steps lead to the final simulation result: a heat transfer analysis of the cross-section of one tube without modeling the heat transfer fluid, a transfer from the cross-section to a simplified one-dimensional radial model and a two-dimensional axial and radial analysis coupling the axial flow of the heat transfer fluid and the radial heat transfer into the storage. 


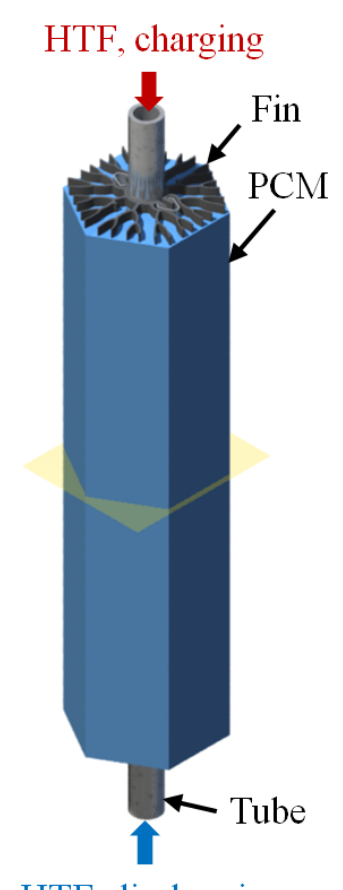

HTF, discharging

(a)

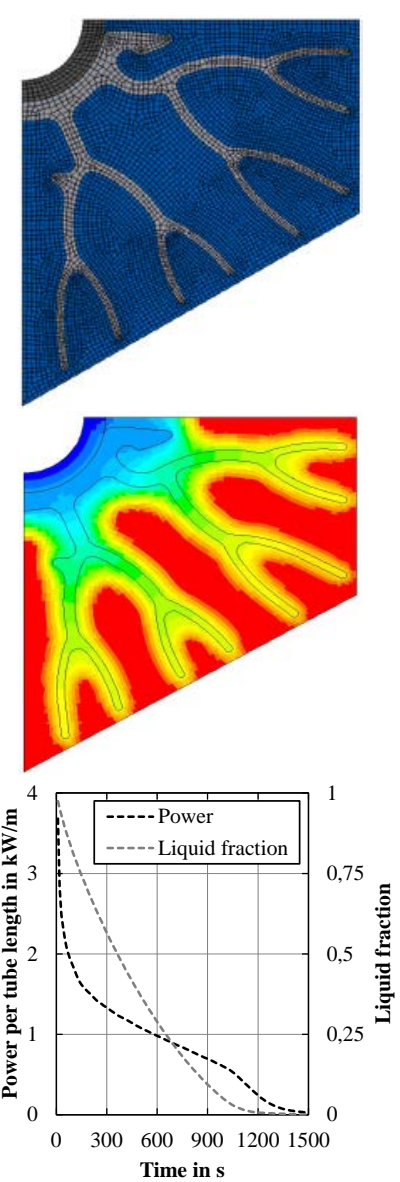

(b)
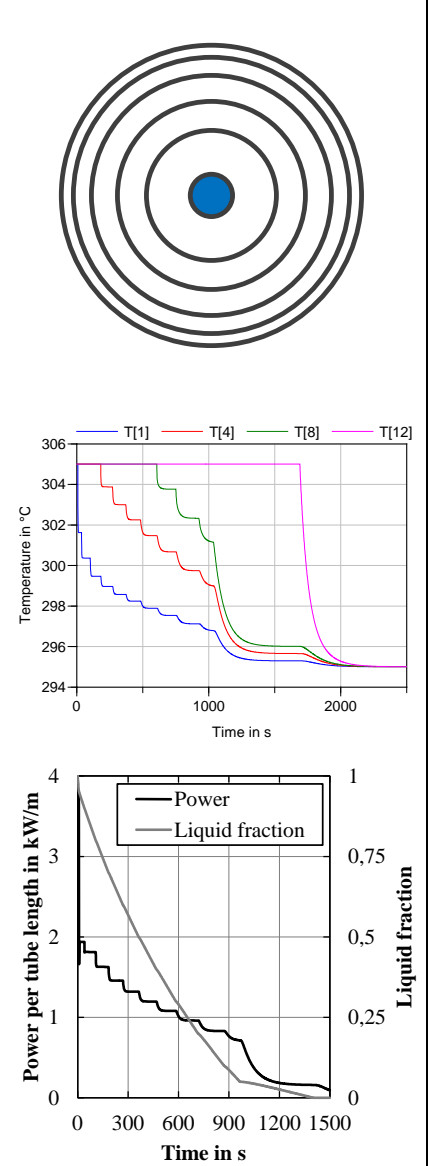

(c)

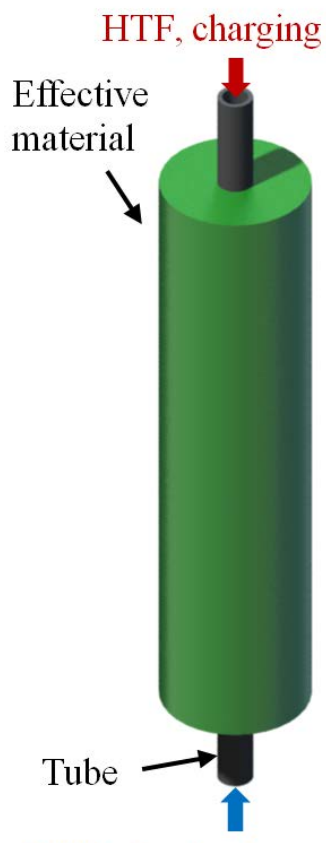

$\mathrm{HTF}$, discharging

(d)

Figure 2: Simulation methodology for a storage system shown in various steps. (a) A single tube assembly, shown here in a shortened form, is created, from which (b) a cross-section is analyzed for heat transfer properties. (c) A transfer of results simplifies the design to a simplified radial model, which is followed by (d) a heat transfer analysis of a tube assembly with coupled axial HTF-flow and a radial conduction model.

The material properties used in these models for this application for the tube, the fin and the PCM at its melting temperature are given in Table 1. The properties of the PCM are mean values of the solid and liquid state near the melting temperature. The mean material properties lead to a maximum deviation of $2.7 \%$ in the thermal diffusivity, which is acceptable for this study and simplifies the modeling approach significantly.

Table 1: Thermodynamic properties of tube, fin, mean values of PCM between solid and liquid state and effective material of PCM and fin.

\begin{tabular}{|ll|r|r|r|r|}
\hline \multicolumn{2}{|l|}{ Property [Unit] $\downarrow /$ Material $\rightarrow$} & $\begin{array}{l}\text { Steel tube } \\
(1.5415)\end{array}$ & $\begin{array}{l}\text { Aluminum fin } \\
(\text { EN AW 6060) }\end{array}$ & $\begin{array}{l}\mathrm{NaNO}_{3} \\
\text { PCM [11] }\end{array}$ & $\begin{array}{l}\text { Effective } \\
\text { material }\end{array}$ \\
\hline Density & {$\left[\mathrm{kg} / \mathrm{m}^{3}\right]$} & 7850 & 2700 & 2010.5 & 2114.5 \\
\hline Spec. heat capacity & {$[\mathrm{J} /(\mathrm{kg} \mathrm{K})]$} & 554 & 1020 & 1655 & 1532.8 \\
\hline Heat conductivity & {$[\mathrm{W} /(\mathrm{m} \mathrm{K})]$} & 45 & 210 & 0.55 & $0.12 \ldots 169$ \\
\hline Latent heat & {$[\mathrm{kJ} / \mathrm{kg}]$} & - & - & 178 & 143.73 \\
\hline
\end{tabular}


The first step of the analysis is a heat transfer analysis of a detailed two-dimensional cross-section with constant boundary conditions, which is conducted using a model implemented in ANSYS $^{\circledR}$ FLUENT $^{\circledR}$. The fin design shown here has two symmetry lines that allow for simplification to a quarter section. For this first step, reference conditions are used. This includes a constant temperature boundary condition on the inside tube wall that results in a fixed temperature difference between the phase change temperature and the discharging temperature. For evaluation, the heat transfer rate and the state of charge (SoC) are recorded over time. These are regarded as characteristic curves for the cross-section. The simulation mesh, simulation state of temperature and the resulting characteristic curves are shown in Figure 2 (b), respectively from top to bottom. These results show qualitatively how the distribution of the aluminum across the cross-section influences the heat transfer. A uniform heat distribution over the area is desirable, so that no pockets of phase change material are left molten while the rest of the area is discharged.

In the second step, simulation results from the cross-section are used to derive a simplified model in Dymola ${ }^{\circledR}$ that replaces the fin and PCM with a single material having effective material properties. The radial discretization, the temperature results over time and the resulting heat flow rate in comparison with the detailed model are shown in Figure 2 (c), respectively from top to bottom. For this model, the domain is also simplified as being axisymmetric, which results in a circular cross-section. The diameter of the cross section varies depending on the hexagonal fin dimensions, such that the area of the circle is equal to the area of the hexagon; for this simulation, the diameter of the circular cross-section is $73.6 \mathrm{~mm}$. The use of polar coordinates and symmetry lead to a one-dimensional discretization into annular rings. The density, the specific heat capacity and the latent heat of the effective material are averaged as in the work of Bauer [12]. However, the heat conductivity calculated this way is too high and results in a faster phase change than with the detailed cross-sectional 
model. Hence, it is adjusted to better fit the detailed fin model. The thermal conductivity in each ring only partially correlates to the fin fraction found in this ring, because the surface area for heat transfer also influences the rate of heat transfer. The conductivity is therefore not calculated from the fin fraction, but is calculated such that the solidification rate in the simplified model corresponds to that in the detailed model. The resulting material properties of the effective material, given as a range from 0.12 to $169 \mathrm{~W} / \mathrm{mK}$ for the thermal conductivity, are given in Table 1 . For the constant reference boundary conditions, the resulting heat flow rate of the simplified one-dimensional (1D) model is shown in comparison to that of the detailed cross-sectional two-dimensional (2D) model in Figure 3. These curves show that the models are in good agreement after an initial numerical roughness. This roughness is due to the discretization in the one-dimensional model and has negligible effects on the system simulations.

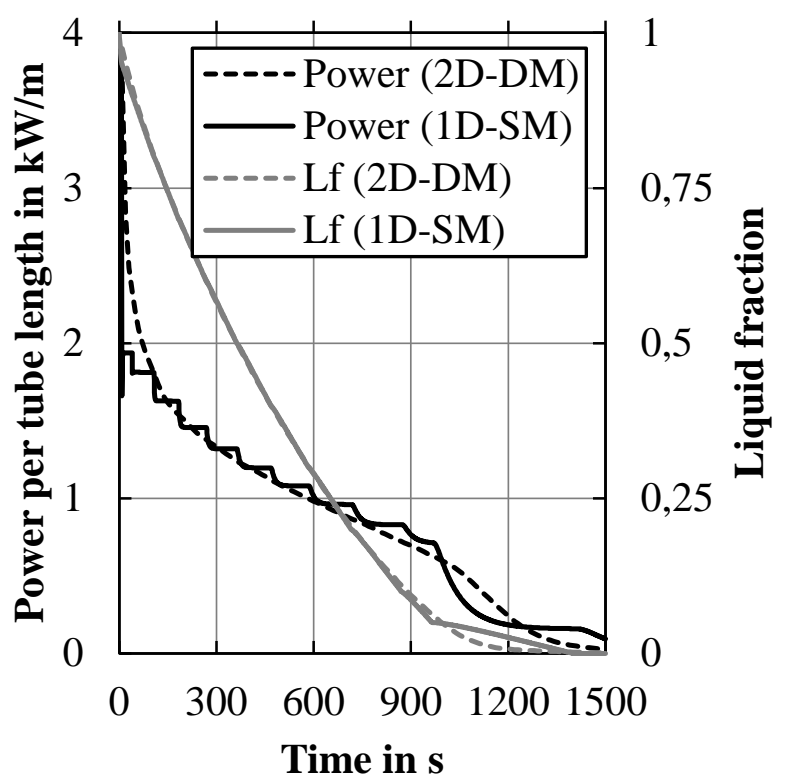

Figure 3: Heat flow rate over time for constant reference boundary conditions in detailed 2D cross sectional model (2D-DM) and simplified 1D model (1D-SM) for power and liquid fraction (Lf).

In the third step, also in Dymola ${ }^{\circledR}$, the entire storage is simulated by coupling the simplified radial effective material model with a model for axial flow of the HTF in the tubes Figure 2 (d). This model is adapted from the model by Stückle, Laing and Müller- 
Steinhagen [13]. This leads to an axisymmetric 2D discretization with cylindrical coordinates for the three-dimensional domain. The number of tubes can be adapted in this step until a sufficient capacity or discharging time is achieved.

\section{RESULTS}

The storage unit for this application has been designed to produce superheated steam for an operating cogeneration plant. The system requires a minimum of 15 minutes for the backup boiler to be powered from cold to full load. The following results are split into a section on the thermal performance analysis of the fin design and the storage simulation and performance.

\subsection{THERMAL PERFORMANCE ANALYSIS OF THE FIN DESIGN}

Various extended finned tube designs were created and analyzed for differing applications. Three designs discussed here are shown in Figure 4, with the critical parameters listed in Table 2.

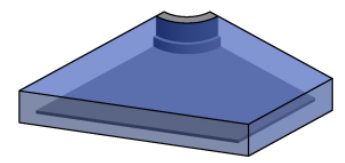

(a)

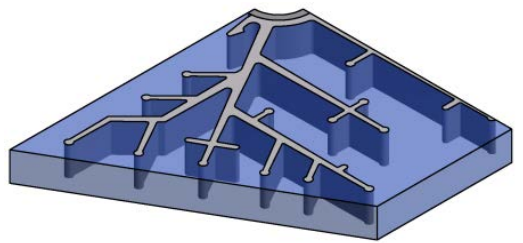

(b)

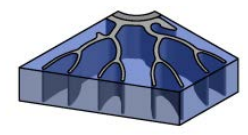

(c)

Figure 4: Three different fin designs and tube spacings: (a) Radial-100, (b) Axial-160 and (c) Axial-70.

The radial fin design in Figure 4 (a) has a tube spacing of $100 \mathrm{~mm}$ and was integrated in the storage documented in [7]. Also documented in this journal article are experiments using the axial fin design with a tube spacing of $160 \mathrm{~mm}$ shown in Figure 4 (b), which was designed for longer charging and discharging times. In comparison, the new fin design shown in Figure 4 (c) shows a much denser aluminum structure and smaller tube spacing. This smaller tube spacing was chosen due to the high power-to-capacity ratio required in the application. 
According to discussions with manufacturers, the smallest tube spacing that can be welded efficiently is $70 \mathrm{~mm}$.

Table 2: Geometric properties and capacities of the fin designs Radial-100, Axial-160 and Axial-70. Capacity calculations made with a $10 \mathrm{~K}$ temperature difference in $\mathrm{NaNO}_{3}$.

\begin{tabular}{|c|c|c|c|c|}
\hline Property [Unit] $\downarrow /$ Fin desig & $n \rightarrow$ & (a) Radial-100 & (b) Axial-160 & (c) Axial-70 \\
\hline Tube spacing & {$[\mathrm{mm}]$} & 100 & 160 & 70 \\
\hline Fin fraction & {$[\%]$} & 7.9 & 14.1 & 17.0 \\
\hline PCM fraction & [\%] & 87.7 & 84.3 & 77.6 \\
\hline Energy per tube length & {$[\mathrm{kWh} / \mathrm{m}]$} & 0.83 & 2.03 & 0.36 \\
\hline Energy per storage volume & {$\left[\mathrm{kWh} / \mathrm{m}^{3}\right]$} & 95.3 & 91.6 & 84.3 \\
\hline Fin mass per capacity & [kg/kWh] & 2.29 & 4.14 & 5.32 \\
\hline
\end{tabular}

For a comparison of the three designs, simulations were conducted at reference conditions, shown in Figure 5. The simulated cycle starts at the melting temperature and discharges to $10 \mathrm{~K}$ below the melting temperature of the simulated storage material. Shown in Figure 5 (a) is a comparison of the power per meter tube for one tube during discharging over the energy transferred during the discharging process; in Figure 5 (b) are results from the same simulations, showing the power per capacity of a storage section over the state-ofcharge (SoC). Due to the differing tube spacings and the differing amounts of aluminum and storage material per extended fin design assembly, these ratio comparisons are necessary. The results comparing the power per tube length in Figure 5 (a) and the energy per tube length in Table 2 show that there is an almost linear relationship (with an $\mathrm{R}^{2}$ value of 0.9969 for the trendline between these points) between the energy transferred during discharge for a single tube and the tube spacing, regardless of the fin fraction, which, as shown in Table 2, ranges from $7.9 \%$ to $17.0 \%$. Energy per unit of storage volume logically decreases with increased fin fraction. For an overall maximized storage capacity, the optimum tube spacing for further storage unit parameters such as mass flow of the HTF must be paired with a minimized fin fraction, which is shown overall in the PCM fraction given in Table 2. 


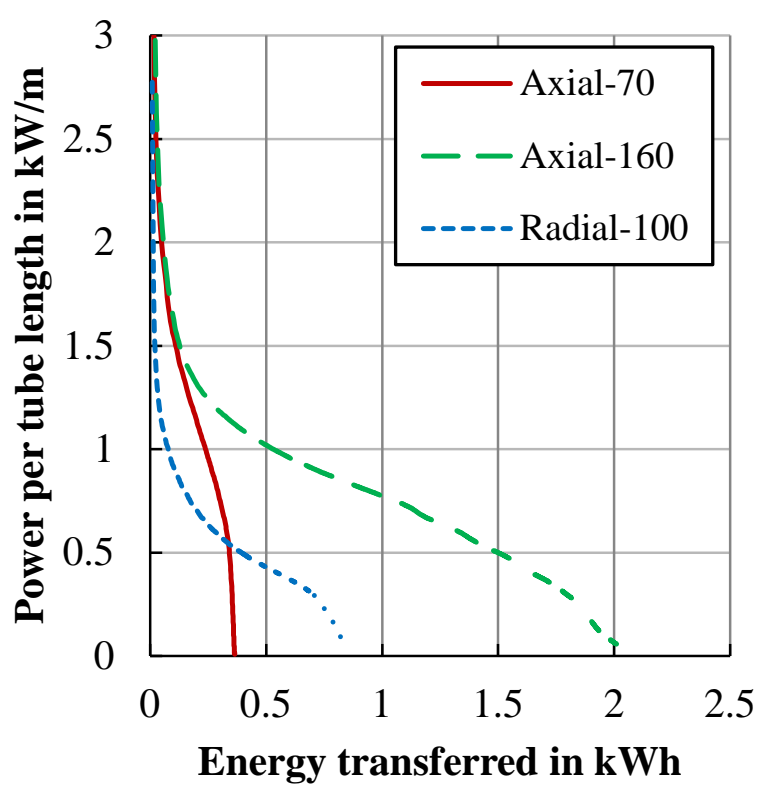

(a)

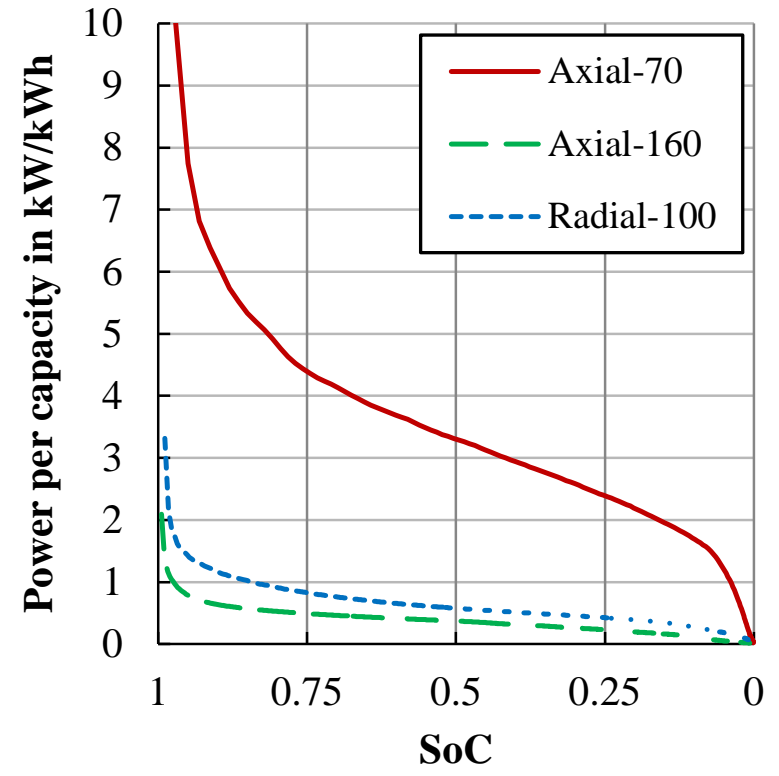

(b)

Figure 5: Three fin design results for (a) power per tube length over energy released and (b) power per capacity over state-of-charge (SoC).

The high power level attained with the new fin design is shown in Figure 5 (b) with the comparison of the power per unit capacity over the state of charge (SoC) of the storage section. The significantly higher power shown by the red solid line is designed to yield the required $6 \mathrm{MW}$ of superheated steam. As the steam temperature is controlled by water injection to meet the temperature requirements, the slope of the red curve during discharging is not critical to this application. The Axial-160 fin design, on the other hand, shows a much lower but more constant power per capacity level throughout discharging.

The Axial-70 fin design is shown in various degrees of discharging in Figure 6 and has an even distribution of aluminum throughout the cross-section and allows for a high power rate during the latent discharging of the storage unit. 


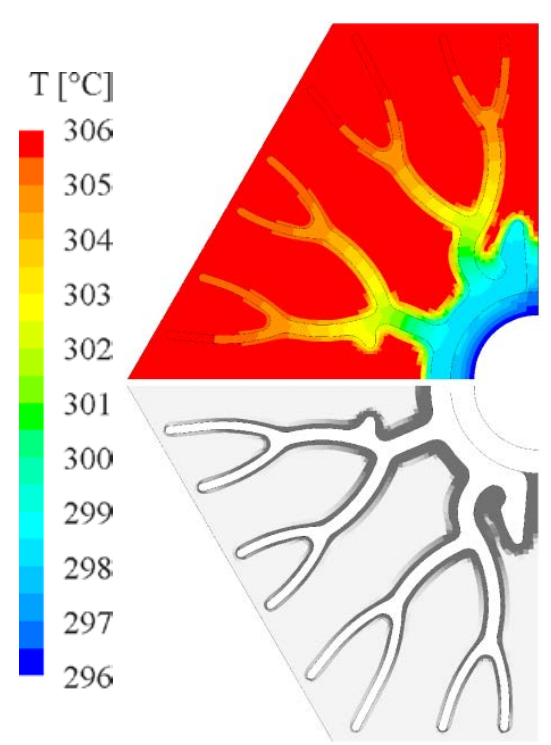

(a)

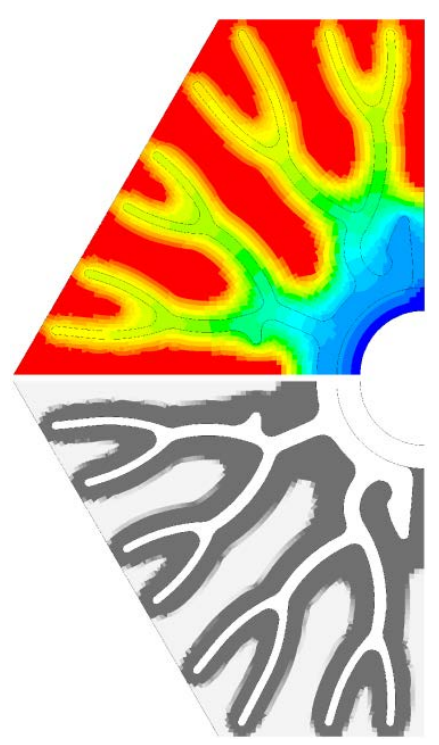

(b)

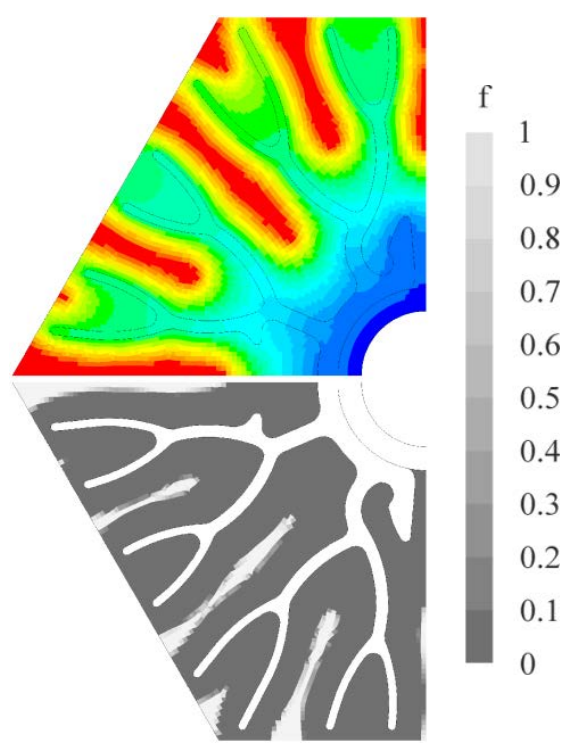

(c)

Figure 6: Temperature $\mathrm{T}$ and liquid phase fraction $\mathrm{f}$ from the detailed cross-sectional model at three different stages of solidification: (a) $82.1 \%$ SoC after $100 \mathrm{~s}$, (b) $40.8 \%$ SoC after $500 \mathrm{~s}$ and (c) $13.9 \%$ SoC after $900 \mathrm{~s}$.

\subsection{STORAGE SIMULATION AND PERFORMANCE}

With the novel fin design, a storage unit is designed and its performance is analyzed with the multi-step simulation model described above. For this application, an inlet feedwater temperature of $103{ }^{\circ} \mathrm{C}$ is used for discharging the storage. During the required discharging duration of at least 15 minutes, the outlet steam temperature must not fall below $300{ }^{\circ} \mathrm{C}$. The storage was designed with an additional discharging time of at least 10 minutes, in total 25 minutes, increasing plant flexibility and introducing a design safety margin. This discharge time correlates to a storage unit made up of 852 finned tubes, each with a fin length of $5.6 \mathrm{~m}$. The simulation results of discharging the storage are shown in Figure 7, where the constant feedwater inlet temperature and the steam outlet temperature are given. The outlet steam temperature reaches the required limit of $300^{\circ} \mathrm{C}$ after 28 minutes, which satisfies the required discharge time and safety margins.

Also shown are the simulated temperatures averaged across the cross-section of the storage material at the top, middle and bottom of the storage material. These temperature distributions show a large difference in temperatures across the storage at the end of 
discharging. Considering the operation in once-through mode, the high fin density and the large temperature difference between the charged storage unit and the inlet feedwater, these temperature distributions are to be expected.
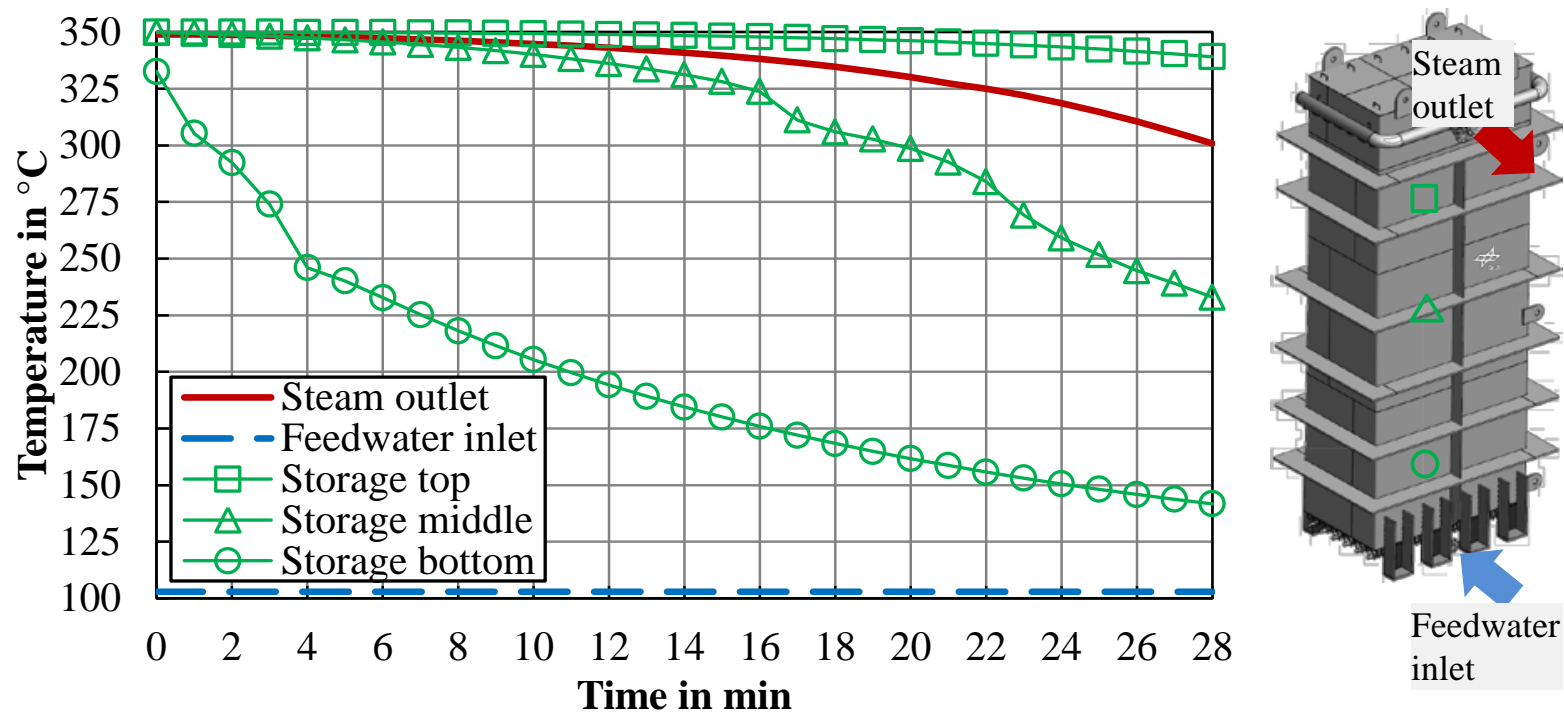

Figure 7: Simulation results during discharging of the inlet and outlet temperatures of the HTF and the temperature distribution over the height of the storage unit, with the schematic at the right showing the approximate positions in relation to the storage unit.

\section{DISCUSSION}

The layout of high temperature latent heat thermal energy storage units needs to be designed for specific system requirements and take into account factors such as feasibility, transient effects, environmental effects and economics. These various factors lead to a challenging design. This paper presents a method for designing latent heat thermal energy storage units for specific application requirements. Specifically, a storage design for a high power and temperature application is detailed for the integration in an operating cogeneration plant. The method shown here can iteratively be used to design a storage unit for system requirements such as power, capacity and temperature. Thermal losses to the environment are not taken into consideration in the current model. For the short discharge duration, these have little effect. However, as the storage is a standby storage, the environmental effects between charging and discharging the storage can be significant for determining the intermediate recharge cycle and optimal insulation. Additional calculations are required for the HTF 
calculations, such as pressure loss and flow distribution, as well as for economic optimizations.

A comparison of the fin fraction and tube spacing between three designs are shown, demonstrating the relationship between material use or surface area and thermal power. The Axial-70 fin design has been produced and is being integrated into a large latent heat thermal energy storage unit being built within the framework of this project. Model validation and analysis will be conducted as a part of the commissioning and testing work.

\section{CONCLUSIONS}

A simulation methodology is presented for the design of high temperature latent heat thermal energy storage units using a multi-step process. The analysis process begins with a preliminary fin design based on system requirements combined with both storage unit and fin extrusion experience. This design is simulated in a two-dimensional ANSYS ${ }^{\circledR}$ FLUENT $^{\circledR}$ model to determine heat transfer and phase change characteristics. This model is then simplified to a one-dimensional Dymola ${ }^{\circledR}$ representation, in which the fin geometry and PCM are converted to effective materials in annular rings about the central tube. As a following step, the ring model is coupled with an HTF model and concatenated axially in order to calculate a single tube, also in Dymola ${ }^{\circledR}$. A storage system using a multiple of the tubes and corresponding initial and system parameters is calculated. With this method, the design and performance analysis of a high temperature latent heat thermal energy storage at a relevant industrial scale has been presented for the first time.

Using this method, the design of the storage unit and storage unit integration and controls has been successfully concluded, resulting in a storage unit with 852 finned tubes, each with a $5.6 \mathrm{~m}$ fin length. The required discharge time of at least 15 minutes will be fulfilled, with a safety margin of more than 10 minutes. The storage unit is currently in build, so that commissioning and testing can be conducted to validate this simulation method. 


\section{ACKNOWLEDGEMENT}

This work has been funded by the German Federal Ministry of Economic Affairs and Energy in the framework of the TESIN project (03ESP011). The authors are responsible for the content of this publication.

A significant portion of this work was presented in paper and presentation form at the Greenstock Conference, Beijing, China in May, 2015.

Present address of Matthias Hempel: QUINTEC Datentechnik GmbH, 90766 Fürth.

\section{REFERENCES}

[1] Johnson M, Vogel J, Hempel M, Dengel A, Seitz M, Hachmann B. High temperature latent heat thermal energy storage integration in a co-gen plant. Energy Procedia 2015;73:281-8. doi:http://dx.doi.org/10.1016/j.egypro.2015.07.689.

[2] Seitz M, Cetin P, Eck M. Thermal Storage Concept for Solar Thermal Power Plants with Direct Steam Generation. Energy Procedia 2014;49:993-1002. doi:10.1016/j.egypro.2014.03.107.

[3] Kenisarin MM. High-temperature phase change materials for thermal energy storage. Renew Sustain Energy Rev 2010;14:955-70. doi:10.1016/j.rser.2009.11.011.

[4] Mehling H, Cabeza LF. Heat and cold storage with PCM. Berlin Heidelberg: Springer; 2008. doi:10.1007/978-3-540-68557-9.

[5] Steinmann W-D, Laing D, Tamme R. Development of PCM Storage for Process Heat and Power Generation. J Sol Energy Eng 2009;131:041009. doi:10.1115/1.3197834.

[6] Laing D, Eck M, Hempel M, Johnson M, Steinmann W, Meyer-Gruenfeld M, et al. High Temperature PCM Storage for DSG Solar Thermal Power Plants Tested in Various Operating Modes of Water/Steam Flow. Sol. PACES Conf., 2012.

[7] Laing D, Bauer T, Breidenbach N, Hachmann B, Johnson M. Development of high temperature phase-change-material storages. Appl Energy 2013;109:497-504. doi:10.1016/j.apenergy.2012.11.063.

[8] Sciacovelli A, Verda V. Second-law design of a latent heat thermal energy storage with branched fins. Int J Numer Methods Heat Fluid Flow 2016;26:489-503. doi:10.1108/HFF-01-2015-0040.

[9] Hübner S, Eck M, Stiller C, Seitz M. Techno-economic heat transfer optimization of large scale latent heat energy storage systems in solar thermal power plants. Appl Therm Eng 2016;98:483-91. doi:10.1016/j.applthermaleng.2015.11.026.

[10] Ziaei S, Lorente S, Bejan A. Morphing tree structures for latent thermal energy storage. J Appl Phys 2015;224901:1-5. doi:10.1063/1.4921442.

[11] Bauer T, Laing D, Tamme R. Characterization of sodium nitrate as phase change material. Int J Thermophys 2012;33:91-104. doi:10.1007/s10765-011-1113-9.

[12] Bauer T. Approximate analytical solutions for the solidification of PCMs in fin 
geometries using effective thermophysical properties. Int $\mathrm{J}$ Heat Mass Transf 2011;54:4923-30. doi:10.1016/j.ijheatmasstransfer.2011.07.004.

[13] Stückle A, Laing D, Müller-Steinhagen H. Numerical Simulation and Experimental Analysis of a Modular Storage System for Direct Steam Generation. Heat Transf Eng 2014;35:812-21. doi:10.1080/01457632.2013.828556. 